\title{
High-dose and low-dose systemic corticosteroids are equally efficient in acute severe asthma
}

\author{
C.-H. Marquette*, B. Stach*, E. Cardot*, J.F. Bervar*, F. Saulnier**, J.J. Lafitte*,
}

High-dose and low-dose systemic corticosteroids are equally efficient in acute severe asthma. C.-H. Marquette, B. Stach, E. Cardot, J.F. Bervar, F. Saulnier, J.J. Lafitte, P. Goldstein, B. Wallaert, A.-B. Tonnel. @ERS Journals 1995.

ABSTRACT: The optimal amount of systemic corticosteroids to be used in acute severe asthma remains an unresolved issue.

In this double-blind, randomized study we compared two doses of methylprednisolone (1 vs 6 mg.kg-1 q.d.) in asthmatics presenting with an acute severe asthma attack, unresponsive to an intensive $\beta_{2}$-agonist regimen administered during a run-in period. Concurrent therapy, including oxygen, inhaled and intravenous salbutamol, and aminophylline was strictly standardized. The response was assessed by serial bedside spirometry. The primary outcome measurement was forced expiratory volume in one second $\left(\mathrm{FEV}_{1}\right)$ (expressed as percentage of predicted values) at 24 and $44 \mathrm{~h}$. The trial was designed in order to achieve a statistical power of $90 \%$.

Twenty three patients were included in the low-dose group and 24 in the highdose group. Both groups were comparable in terms of demographic profiles, history of asthma, and severity of the current attack. Improvement in pulmonary function was similar in both groups. At $44 \mathrm{~h}$, the mean $( \pm S D) F_{1} V_{1}$ values were $53 \pm 22$ and $45 \pm 14 \%$ in the low and in the high-dose group respectively (NS).

We conclude that high dose systemic corticosteroids offer no further benefit over low-doses in the treatment of severe acute asthma.

Eur Respir J., 1995; 8, 22-27.
*Dépt de Pneumologie and **Service d'Urgence Respiratoire et de Réanimation Médicale, Hôpital A. Calmette, C.H.R.U. de Lille, France. †Service d'Aide Médicalisée d'Urgence (SAMU), C.H.R.U. de Lille, France.

Correspondence: Ch.H. Marquette

Dépt de Pneumologie

Hôpital A. Calmette

C.H.R.U. de Lille

59037 Lille Cedex

France

Keywords: Asthma corticosteroids

Received: April 51994

Accepted after revision September 281994

This work was supported by the C.H.R.U de Lille, by the Société pour l'Enseignement et la Recherche en Pneumologie et Allergologie and by INSERM (CJF 90 06).
Treatment of acute severe asthma is now well-established, and comprises use of $\beta_{2}$-agonists and systemic corticosteroids (CS). Intensive $\beta_{2}$-agonist therapy is particularly effective in alleviating acute bronchospasm, but does not reverse bronchial inflammation, which is a major component of airway obstruction in severe asthma. Despite few exceptions, there is now compelling evidence that the treatment of the inflammatory component depends upon the use of corticosteroids [1-6]. Thus, practice guidelines widely recommend the use of CS in the management of acute severe asthma, especially in patients refractory to intensive $\beta_{2}$-agonists therapy [7], but the optimal amount of CS to be used remains an unresolved issue [8-22]. The doses used or recommended in the recent literature vary from as little as $15 \mathrm{mg}$ to as much as $1,000 \mathrm{mg}$ of prednisone or equivalent per day $[7,20,23]$, with a current trend to increase the doses. Although high doses of CS are usually secure, the more is not necessarily the better in acute severe asthma.

The major side-effects of CS are transient hyperglycaemia and acute psychosis. Sudden deaths have also been reported, especially with high-dose pulse therapy, that are presumably related to cardiac arrhythmias triggered by acute electrolyte shifts. This risk is of concern, especially in the hypoxic conditions of acute severe asthma, since both cardiac adverse effects and hypokalaemia can be augmented by the concomitant use of $\beta_{2}$-agonists [24]. More importantly, recent human and animal studies indirectly support the evidence that the acute myopathy, which is increasingly reported in patients receiving mechanical ventilation for status asthmaticus, is caused by a previously unrecognized interaction between neuromuscular blocking agents and high dose corticosteroids [25]. These potential hazards of high-dose CS, together with the uncertainties regarding the dose-response relationship, justify the reappraisal of the current dosing regimens used in acute severe asthma.

This prospective double-blind, randomized trial compared the respective efficacy of a low and a high dose of intravenous methylprednisolone (1 vs $6 \mathrm{mg} \cdot \mathrm{kg}^{-1}$ q.d) in adults hospitalized with acute severe asthma.

\section{Methods}

\section{Eligibility of patients and run-in period}

All patients aged 18-65 yrs presenting with acute severe asthma were considered eligible for the study. 
The diagnosis of asthma was based on a typical history [26], together with significant reversibility of airway obstruction (defined as a change in forced expiratory volume in one second $\left(\mathrm{FEV}_{1}\right) \geq 15 \%$ of predicted value, or $\geq 25 \%$ of baseline value). This latter requirement was to be documented by spirometric measurements performed during previous or subsequent follow-up visits. Patients were excluded if they had received parenteral CS prior to admission, if they were considered to require prompt ventilatory support, if they had fever $\left(\geq 38^{\circ} \mathrm{C}\right)$ or chest $\mathrm{X}$-ray abnormalities on admission, or if they had the following known or suspected conditions: chronic bronchitis, emphysema, extrapulmonary infection, pregnancy, diabetes mellitus, peptic ulcer, smoking history with more than 15 pack-years, present or past psychiatric problems.

On admission, patients were started on a standardized regimen of intensive $\beta_{2}$-agonists: salbutamol $5 \mathrm{mg}$ in 5 $\mathrm{ml}$ of normal saline solution over $15 \mathrm{~min}$, administered via a face mask nebulizer driven by compressed oxygen at a flow of $8 l \cdot \mathrm{min}^{-1}$, together with salbutamol 0.25 $\mathrm{mg} \cdot \mathrm{h}^{-1}$ via continuous intravenous (i.v.) infusion. Thirty minutes after the end of the nebulization, $\mathrm{FEV}_{1}$ was measured with a portable spirometer (Fukuda ST 90, Sanyo) by a trained member of the nursing staff. This postbronchodilator $\mathrm{FEV}_{1}$ measured at completion of the runin period was defined as the baseline $\mathrm{FEV}_{1}$ for the purpose of the study. Only the patients with a baseline FEV, $\leq 50 \%$ of predicted value ( $\%$ pred) were included. This run-in period allowed us to exclude the subset of asthmatics experiencing rapid alleviation of severe bronchospasm with high-dose $\beta$-agonists alone.

All the patients were examined on admission by one of the investigators (BS or CHM). Informed consent was obtained from each patient. The study was approved by our hospital Human-Research Committee.

\section{Treatment regimen}

Immediately upon inclusion, the patients were randomly assigned to receive $1 \mathrm{mg} \cdot \mathrm{kg}^{-1} q . d$. (low-dose group) or $6 \mathrm{mg} \cdot \mathrm{kg}^{-1} q . d$. (high-dose group) of methylprednisolone during the first $48 \mathrm{~h}$. Since the galenic form (lyophilized powder) was not well suited for blind preparation of weight-adapted doses we proceeded as follows: sterile opaque vials containing either $20 \mathrm{mg}$ (low-dose group) or $120 \mathrm{mg}$ (high-dose group) of methylprednisolone (Solumedrol (0) were prepared by the Centre Régional de Transfusion Sanguine de Lille and prepackaged in individual sets containing the treatment for the study period for each individual patient (eight vials). The sets and the vials could only be identified by a random number. Before each administration of methylprednisolone, the powder contained in the vials was diluted in $10 \mathrm{ml}$ of sterile water. The injected volume of this final dilution depended upon the patient's weight. Patients weighing $\leq 60 \mathrm{~kg}$ received $7.5 \mathrm{ml}$ intravenously every $6 \mathrm{~h}$; patients weighing $>60 \leq 80 \mathrm{~kg}$ received $8.5 \mathrm{ml}$ every 6 $\mathrm{h}$; and patients weighing $>80 \mathrm{~kg}$ received $10 \mathrm{ml}$ every 6 h. By following this procedure, the patients in the low dose group received approximately $1 \mathrm{mg} \cdot \mathrm{kg}^{-1} q . d$. of methylprednisolone, and the patients in the high dose group received approximately $6 \mathrm{mg} \cdot \mathrm{kg}^{-1}$ q.d. All patients, investigators and medical staff were blind to the dose administered.

The study lasted $44 \mathrm{~h}$ after the first dose was given. At completion of the study, CS were continued at a dose determined by the attending physician. Concurrently with the CS, all subjects were administered a standardized treatment consisting of a parenteral $5 \%$ solution of dextrose in water $1 l \cdot$ day $^{-1}$ with potassium chloride supplement $\left(2 \mathrm{~g} \cdot \mathrm{day}^{-1}\right)$ and aminophylline $10 \mathrm{mg} \cdot \mathrm{kg}^{-1}$ q.d. Salbutamol was administered by continuous $i . v$. infusion $\left(0.25 \mathrm{mg} \cdot \mathrm{h}^{-1}\right)$ initially, and also by face mask nebulizations ( $5 \mathrm{mg}$ administered over $15 \mathrm{~min}$ ) every $4 \mathrm{~h}$ during the first day, and every $6 \mathrm{~h}$ thereafter. If the clinical status worsened, the infusion rate of salbutamol was increased (up to $1 \mathrm{mg} \cdot \mathrm{h}^{-1}$ ) as needed. Oxygen was administered via nasal prongs, at an initial flow of $6 l \cdot \mathrm{min}^{-1}$, and subsequently adjusted on clinical data and arterial blood gas results in order to maintain oxygen saturation above $90 \%$. Antibiotics were prescribed only if bronchial infection was suspected by history and by the presence of purulent sputum.

\section{Baseline and follow-up evaluation}

Pretreatment evaluation included a complete history and physical examination, complete blood cell count, urea, creatinine, electrolyte and glucose levels, arterial blood gas, chest roentgenogram and electrocardiography (ECG). Steroid dependence of asthma was defined as asthma of a severity needing an average daily dose of $10 \mathrm{mg}$ of prednisone or equivalent during the previous year. The diagnosis of aspirin-sensitive asthma was retained if the patient previously experienced a typical history of nasal and/or bronchospastic reaction following the ingestion of aspirin or nonsteroidal anti-inflammatory drugs. There was no attempt to measure $\mathrm{FEV}_{1}$ directly on admission. Indeed, this accurate spirometric measurement requires a good co-operation that could not be expected before any therapeutic intervention (i.e. oxygen and bronchodilators) in a patient experiencing an acute attack of asthma. Therefore $\mathrm{FEV}_{1}$ was first measured at completion of the run-in period (baseline $\mathrm{FEV}_{1}$ ). Subsequent bedside spirometry was performed before and after each nebulization of salbutamol thereafter, i.e. every $4 \mathrm{~h}$ during the first $24 \mathrm{~h}$ of the study, and then every $6 \mathrm{~h}$ until the end of the study. Blood pressure and pulse were measured before and after each nebulization of salbutamol. Respiratory rate, electrolyte and glucose levels were measured at 24 and $48 \mathrm{~h}$. Arterial blood gas, complete blood cell count, chest roentgenogram and ECG were obtained at the end of the evaluation period.

\section{Statistical analysis}

Differences between the groups in characteristics at baseline and during the study were assessed with the chi-squared test for categorical variables. For continuous variables, paired and unpaired two-sided t-tests were 
used, respectively, for comparisons within treatment groups between times, and for comparisons between treatment groups at different times. A p-value of less than 0.05 was considered to indicate statistical significance.

The primary outcome measurement determined at the start of the study was the improvement of the $\mathrm{FEV}_{1}$ expressed as percentage of predicted value (\% pred) at $24 \mathrm{~h}$. In a preliminary open study, we could estimate that with the low dose $\left(1 \mathrm{mg} \cdot \mathrm{kg}^{-1}\right.$ q.d.), the mean $( \pm \mathrm{SD})$ postbronchodilator $\mathrm{FEV}_{1}$ value (expressed as \% predicted) to be expected at $24 \mathrm{~h}$ was $48 \pm 21 \%$. Hence, to detect a difference of $20 \%$ predicted in $\mathrm{FEV}_{1}$ between the two groups with a two-sided significance level of 0.05 and a power of $90 \%$ a total of 46 patients would be needed.

\section{Results}

\section{Study population}

A total of 52 consecutive patients entered the study between May 15, 1990 and June 31, 1992 (low-dose group, $n=26$; high-dose group, $n=26$ ). As a whole, the study population represented $22 \%$ of the patients presenting with acute severe asthma during the study period. The main reasons preventing inclusion into the study were the administration of parenteral CS before hospitalization, rapid alleviation of bronchospasm with intensive $\beta_{2}$-agonists alone, and the presence of fever or chest $\mathrm{X}$-ray abnormalities upon admission. All the patients had taken more than 10 puffs of a $\beta_{2}$-agonist metereddose inhaler and had received subcutaneous terbutaline from a general practitioner or from the emergency ambulance doctor.

Fifty one patients completed the study protocol. One patient was withdrawn from the study at $12 \mathrm{~h}$ because of the occurrence of fever. Four patients, two in each group, were excluded from the analysis because of erroneous inclusion. These four patients did not fulfil the criteria for asthma at subsequent follow-up. The diagnosis of acute exacerbation of chronic obstructive pulmonary disease (COPD) was retained in these patients. Thus, a total of 47 patients, 23 in the low dose group and 24 in the high dose group were finally assessable. Table 1 shows the baseline characteristics in these patients. There was no difference between the two groups in demographic profiles and history of asthma. The severity of the attack assessed by the respiratory rate, the blood gas values and, especially, the baseline $\mathrm{FEV}_{1}$ (postbronchodilator $\mathrm{FEV}_{1}$ measured at completion of the run-in period) were similar in the two groups.

\section{Outcome and adverse effects}

Compared with baseline spirometric values, both groups markedly improved over time. Differences in $\mathrm{FEV}_{1}$ became statistically significant from baseline within $8 \mathrm{~h}$ of treatment in both groups. At $24 \mathrm{~h}$, the mean $( \pm \mathrm{SD})$ prebronchodilator $\mathrm{FEV}_{1}$ values (expressed as percentage
Table 1. - Characteristics of patients at entry into the study

\begin{tabular}{|c|c|c|}
\hline Characteristic & $\begin{array}{l}\text { Low-dose } \\
\text { group }\end{array}$ & $\begin{array}{l}\text { High-dose } \\
\text { group }\end{array}$ \\
\hline $\mathrm{n}$ & 23 & 24 \\
\hline Age yrs & $38 \pm 11$ & $40 \pm 14$ \\
\hline $\operatorname{Sex} M / F$ & $9 / 14$ & $15 / 9$ \\
\hline Duration of asthma yrs & $16 \pm 14$ & $20 \pm 15$ \\
\hline Atopic subjects & 17 & 18 \\
\hline Corticosteroid-dependant asthma & 2 & 2 \\
\hline Aspirin-sensitive asthma & 5 & 1 \\
\hline Current smokers & 1 & 4 \\
\hline $\begin{array}{l}\text { Patients previously hospitalized } \\
\text { for acute severe asthma* }\end{array}$ & $14(2)$ & $18(5)$ \\
\hline Postbronchodilator $\mathrm{FEV}_{1} \%$ pred & $32 \pm 11$ & $27 \pm 8$ \\
\hline$f_{\mathrm{R}}$ breaths $\cdot \mathrm{min}^{-1}$ & $20 \pm 5$ & $21 \pm 5$ \\
\hline Heart rate beats $\cdot \min ^{-1}$ & $99 \pm 12$ & $101 \pm 18$ \\
\hline Systolic BP $\mathrm{mmHg}$ & $145 \pm 22$ & $148 \pm 24$ \\
\hline Diastolic $\mathrm{BP} \mathrm{mmHg}$ & $86 \pm 14$ & $88 \pm 18$ \\
\hline Arterial $\mathrm{pH}$ & $7.40 \pm 0.05$ & $7.38 \pm 0.06$ \\
\hline $\mathrm{PaCO}_{2} \quad \mathrm{kPa}$ & $5.6 \pm 0.8$ & $5.7 \pm 1.6$ \\
\hline Blood glucose $\mathrm{mmol} \cdot l^{-1}$ & $6.38 \pm 2.69$ & $7.04 \pm 1.99$ \\
\hline WBC count $10^{9} \cdot l^{-1}$ & $10.6 \pm 3.4$ & $12.4 \pm 4.5$ \\
\hline
\end{tabular}

Values of continuous variables are expressed as mean \pm sD. M: male; F: female; $\mathrm{FEV}_{1}$ : forced expiratory volume in one second; $\mathrm{BP}$ : blood pressure; $\mathrm{PaCO}_{2}$ : arterial carbon dioxide tension; WBC: white blood cells; $f_{\mathrm{R}}$ : respiratory rate. *: with mechanical ventilation required.

predicted) were $52 \pm 26$ and $42 \pm 14 \%$ in the low-dose group and high-dose group, respectively (NS). At $44 \mathrm{~h}$, the mean $( \pm \mathrm{SD})$ prebronchodilator $\mathrm{FEV}_{1}$ values were $53 \pm 22$ and $45 \pm 14 \%$ in the low-dose group and in the highdose group, respectively (NS). At $24 \mathrm{~h}$, postbronchodilator $\mathrm{FEV}_{1}$ values were $59 \pm 26$ and $51 \pm 17 \%$ in the low-dose group and in the high dose group, respectively, (Ns); and $60 \pm 27$ and $50 \pm 16 \%$ (NS) at $44 \mathrm{~h}$ (Fig. 1). The postbronchodilator $\mathrm{FEV}_{1}$ was always significantly higher than the prebronchodilator $\mathrm{FEV}_{1}$ in the high-dose group, and in 5 out of 9 measurements (at 4, 20, 26, 38 and $44 \mathrm{~h}$ ) in the low-dose group. The percentage of patients reaching a postbronchodilator $\mathrm{FEV}_{1} \geq 50 \%$ predicted value at each time interval was similar in the two groups. This was also true for the prebronchodilator $\mathrm{FEV}_{1}$, except at $8 \mathrm{~h}$ when significantly more patients had reached this level of $\mathrm{FEV}_{1}$ in the low-dose group (11 out of 23 versus 3 out of $24 ; \mathrm{p}<0.05)$. Excluding from the analysis the four asthmatics who were steroid-dependent (two in each group) did not modify these results.

Respiratory rates which were similar on admission $\left(20.4 \pm 5\right.$ vs $21 \pm 5$ breaths $\left.\cdot \mathrm{min}^{-1}\right)$ decreased significantly $(\mathrm{p}<0.001)$, and with the same magnitude in both groups (17.5 \pm 3 breaths $\cdot \mathrm{min}^{-1}$ in the low-dose group and 17.1 \pm 3.6 breaths $\cdot \mathrm{min}^{-1}$ in the high-dose group at $24 \mathrm{~h}$ ).

All patients were discharged alive, with a mean duration of hospitalization of $7.1 \pm 3$ days in the low-dose group and 8.2 \pm 3.8 days in the high-dose group (NS). No acute respiratory failure requiring mechanical ventilation was observed. Secondary worsening of bronchospasm was, however, observed after $24 \mathrm{~h}$ of treatment in one patient in the high-dose group, and after $48 \mathrm{~h}$ of treatment in one patient in the low-dose group. Both patients responded well to a twofold increase of $\beta_{2}$-agonist doses. 
a)

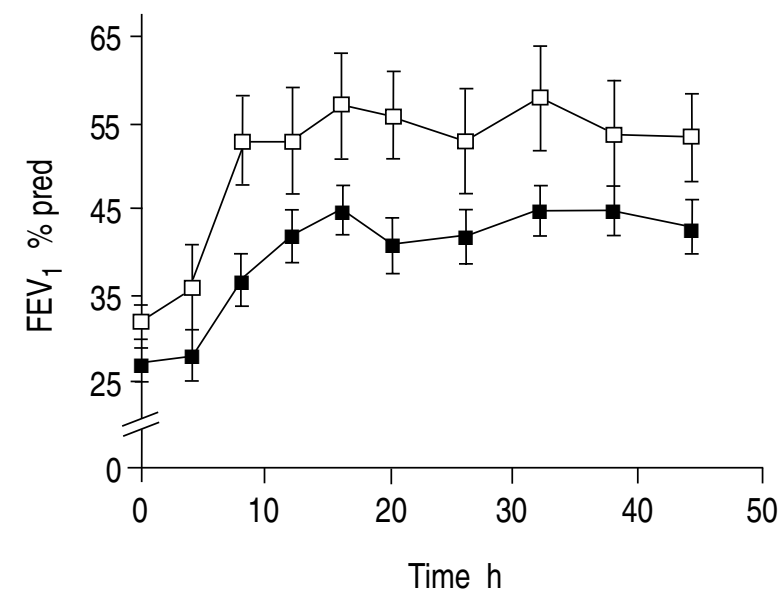

b)

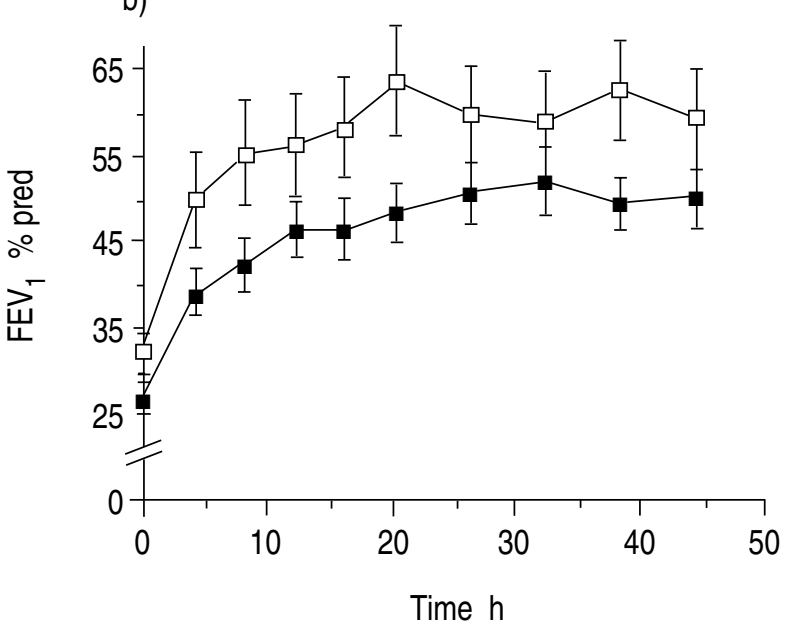

Fig. 1. - Time-course of improvement of the patients as assessed by serial bedside spirometry. a) FEV measured before each nebulization of salbutamol administered every $4 \mathrm{~h}$ during the first $24 \mathrm{~h}$, and every $6 \mathrm{~h}$ thereafter. b) FEV $\mathrm{f}_{1}$ measured 30 min after each nebulization of salbutamol administered every $4 \mathrm{~h}$ during the first $24 \mathrm{~h}$ and every $6 \mathrm{~h}$ thereafter. The FEV $\mathrm{F}_{1}$ at time zero was the "baseline FEV ${ }_{1}$ (see Methods for definition). $\mathrm{FEV}_{1}$ : forced expiratory volume in one second; \% pred: percentage of predicted. $\mathbf{\square}$ : low-dose group: $\square$ : high-dose group.

One patient in the low-dose group developed acute delirium by the end of the study. This patient had been treated for several years for chronic psychosis but denied psychiatric problems. Thus, neuroleptics were inadvertently stopped on admission. No patient experienced cardiovascular or gastric adverse effects. Compared to baseline values (table 1) glucose levels significantly increased at $24 \mathrm{~h}\left(10.6 \pm 4.1 \mathrm{mmol} \cdot \mathrm{l}^{-1}\right.$ in the low-dose group vs $11.1 \pm 5.5 \mathrm{mmol} \cdot l^{-1}$ in the high-dose group; Ns) and at $44 \mathrm{~h}\left(9.8 \pm 4.7 \mathrm{mmol} \cdot \mathrm{l}^{-1}\right.$ in the low-dose group $v s$ $10 \pm 5.4 \mathrm{mmol} \cdot l^{-1}$ in the high-dose group; Ns). One patient in the high-dose group, known to have an impaired glucose tolerance, developed severe hyperglycaemia which required prolonged insulin therapy. No significant hypokalaemia was observed. Finally, a marked increase in white blood cell (WBC) count was observed by the end of the study, which was significantly higher in the high-dose group $\left(21.8 \pm 5.8\right.$ vs $\left.15.5 \pm 5.5 \times 10^{9} \cdot l^{-1} ; \mathrm{p}<0.05\right)$ although in this group there were fewer patients with suspected bronchitis (4 vs 7).

\section{Discussion}

As recently reviewed by MCFADDEN [11] in a detailed analysis of the available data on steroid pharmacodynamics in asthma, the entire issue of the optimal dose of $\mathrm{CS}$ in severe acute asthma is unresolved. Unlike other drugs, such as $\beta_{2}$-agonists, there is no pharmacological rationale supporting the use of high doses of CS. Moreover, there is recent evidence suggesting that increasing the doses of CS carries the risk of serious adverse effects in severe acute asthma [24, 25].

Despite a power of $90 \%$ this double-blind, randomized trial could not establish a beneficial effect of high dose CS, compared with low dose CS, in treating severe acute asthma. Our results were at least partly predictable based upon the information in the literature. However, as thoroughly discussed by WARD [9] and by ENGEL and
HeINIG [10], beside the fact that most of the previous trials addressing this issue were unblinded, they had a considerable chance of not being able to detect a clinically relevant difference between different dosing regimens because of a large type II error due to methodological flaws [12-15, 17-21]. Firstly, in view of the mode of action of CS at the molecular level, and given the time course of improvement with CS, at least $12 \mathrm{~h}$ are necessary to document changes in pulmonary function depending upon corticosteroids per se [3]. Secondly, as the rate of recovery from an attack of asthma varies considerably from patient to patient, the standard deviation of changes in pulmonary function within a group of treated patients is large. This entails the need for a sufficient number of patients to be studied in order to avoid the risk of a large type II error (low power).

The study protocol was designed as recommended [9, 10], in order to accurately compare the effectiveness of two doses of CS. The drug regimens administered concurrently to CS were strictly standardized. Since a certain subset of asthmatics rapidly respond to intensive $\beta_{2}$-agonists alone [27], we included only patients unresponsive to $\beta_{2}$-agonists, in order not to blunt the effects specifically exerted by the CS. To minimize the variability of the measurement of the response, we used spirometry $\left(\mathrm{FEV}_{1}\right)$ instead of peak flow or dyspnoea score recordings. The final means chosen to lessen the type II error was to limit the number of regimens to be compared (i.e. two doses instead of three or more).

Among the studies which have investigated the dose effects of CS in severe acute asthma [12-22], only two $[16,22]$ satisfy most of the methodological standards recommended by WARD [9], and by ENGEL and HEINIG [10]. Both studies evaluated only patients unresponsive to $\beta_{2}$-agonists, but, unlike our study, strict spirometric criteria were not required. Despite this, the severity of the asthma attacks as assessed by the prestudy $\mathrm{FEV}_{1}$ was similar in these two studies and in the present study. Concurrent therapy included i.v. aminophylline and 
nebulized salbutamol, but no additional i.v. salbutamol. The doses of CS were not related to the patients' weight. In the study by Bowler et al. [22], the low, medium and high dose groups included, respectively, 22, 20 and 24 patients, who received, respectively, 50,100 and $500 \mathrm{mg}$ of $i . v$. hydrocortisone every $6 \mathrm{~h}$ (equivalent to 40, 80, and $400 \mathrm{mg}$ of methylprednisolone daily). No significant difference in $\mathrm{FEV}_{1}$ was detected at 24 and $48 \mathrm{~h}$ between the three groups. Our results accord with these findings. Although we studied fewer patients, the comparison of two groups instead of three results in a higher statistical power (lower type II error), hence adding confidence to our findings. In the study by HASKELl et al. [16] three doses of methylprednisolone (60, 160 and $500 \mathrm{mg} \cdot \mathrm{day}^{-1}$ administered i.v. in four divided doses) were compared in three groups of only eight patients each. There was no difference in $\mathrm{FEV}_{1}$ between the three groups by the end of Day 2. An apparently faster improvement, documented by a higher percentage of patients with a $\mathrm{FEV}_{1} \geq 50 \%$ predicted by the end of Day 2, was reported with the medium and the high dose. Neither BOwLER et al. [22] nor we could confirm these findings.

As in the previous studies, there was no difference between groups with respect to adverse effects.

There are several areas of potential concern with the design of this study. Firstly, we did not include the asthmatics who had received parenteral CS and those who required mechanical ventilation. Thus, our findings might not be applicable to the most severe asthma attacks. Conversely, although the asthmatics responding to $\beta_{2}$-agonists alone were not studied, we can reasonably infer from our results that high dose CS would not add any benefit compared to low doses in such patients. Secondly, the run-in period designed to exclude the patients who would respond to $\beta_{2}$-agonists alone can be considered as too short. Indeed, in the study by FANTA et al. [3] the run-in period was longer. However, given the large amounts of $\beta_{2}$-agonists received by the patients before hospitalization and during the run-in period, and given the rapid onset of action of these drugs, we believe that prolonging the run-in period would not have resulted in many additional exclusions. Thirdly, the doses we chose to investigate may have been inappropriate. The "low" dose we chose was very similar to the low dose used by Bowler et al. [22], and by HASKELl et al. [16]. We actually chose the same "high" dose as HASKEL et al. [16], which was already higher than the dose used by FANTA et al. [3] in the study which unequivocally demonstrated the benefits of CS. In addition, we adapted the doses to the patient's weight, in order to allow for this latter factor of variability. Accordingly, it seems improbable that our "high" dose was insufficient to demonstrate a beneficial effect. Finally, the study period may have been too short to demonstrate a beneficial effect of the higher dose. This is improbable, since the trend at completion of the study was in favour of a higher improvement with the low dose regimen.

In summary, the present study clearly confirms that high doses of corticosteroids offer no further benefit over low doses in patients with acute severe asthma. Acknowledgements: The authors thank the Centre Régional de transfusion from Lille for its help in providing the blind preparations of methylprednisolone.

\section{References}

1. Medical Research Council: Controlled trial of effects of cortisone acetate in chronic asthmaticus. Lancet 1956; 20: 803-806.

2. Pierson WE, Bierman CW, Kelley VC. A double-blind trial of corticosteroid therapy in status asthmaticus. Pediatrics 1974; 54: 282-288.

3. Fanta $\mathrm{CH}$, Rossing TH, McFadden ER. Glucocorticoids in acute asthma. Am J Med 1983; 74: 845-881.

4. Littenberg B, Gluck EH. A controlled trial of methylprednisolone in the emergency treatment of acute asthma. N Engl J Med 1986; 314: 150-152.

5. Lundgren JD, Kaliner MA, Shelhamer JH. Mechanisms by which glucocorticosteroids inhibit secretion of mucus in asthmatic airways. Am Rev Respir Dis 1990; 141: S52-58.

6. Schleimer RP. Effects of glucocorticosteroids on inflammatory cells relevant to their therapeutic applications in asthma. Am Rev Respir Dis 1990; 141: S59-59.

7. National Asthma Education Program. Expert panel report. Guidelines for the Diagnosis and Management of Asthma. US Department of Health and Human Services. Publication No. 91-3042. August, 1991.

8. Conférence de Consensus en Réanimation et Medecine d'Urgence. Prise en charge des crises d'asthme aiguës graves de l'adulte. Réan Soins Intens Méd Urg 1989; 5: 25-31.

9. Ward MJ. Clinical trials in acute severe asthma: are type II errors important? Thorax 1986; 41: 824-829.

10. Engel T, Heinig JH. Glucocorticosteroid therapy in acute severe asthma. a critical review. Eur Respir J 1991; 4: 881-889.

11. McFadden ER. Dosages of corticosteroids in asthma. Am Rev Respir Dis 1993; 147: 1306-1310

12. Britton MG, Collins JV, Brown D, Fairhurst NPA, Lambert RG. High-dose corticosteroids in severe acute asthma. Br Med J 1976; 2: 73-74.

13. McFadden E, Kiser R, de Groot WJ, Holmes B, Kiker R, Viser G. A controlled study of the effects of single doses of hydrocortisone on the resolution of acute attacks of asthma. Am J Med 1976; 60; 52-59.

14. Harfi H, Hanissian AS, Crawford LV. Treatment of status asthmaticus in children with high doses and conventional doses of methylprednisolone. Pediatrics 1978; 61: 829-831.

15. Tanaka RM, Santiago SM, Kuhn GJ, Williams RE, Klaustermeyer WB. Intravenous methylprednisolone in adults in status asthmaticus. Chest 1982; 82: 438440.

16. Haskell RJ, Wong BM, Hansen JE. A double-blind, randomized clinical trial of methylprednisolone in status asthmaticus. Arch Intern Med 1983; 143: 13241327.

17. Harrison BD, Hart GJ, Ali NJ, Stokes TC, Vaughan DA, Robinson AA. Need for intravenous hydrocortisone in addition to oral prednisolone in patients admitted to hospital with severe asthma without ventilatory failure. Lancet 1986; 25: 181-184.

18. Raimondi AC, Figueroa-Casas JC, Roncoroni AJ. 
Comparison between high and moderate doses of hydrocortisone in the treatment of status asthmaticus. Chest 1986; 89: 832-835.

19. Webb JR. Dose response of patients to oral corticosteroid treatment during exacerbations of asthma. $\mathrm{Br} \mathrm{Med}$ $J$ 1986; 292: 1045-1047.

20. Ratto D, Alfaro C, Sipsey J, Glovsky MM, Sharma OP. Are intravenous corticosteroids required in status asthmaticus? Jama 1988; 260: 527-529.

21. Engel T, Dirksen A, Frolund L, et al. Methylprednisolone pulse therapy in acute severe asthma. A randomized, double-bind study. Allergy 1990; 45: 224-230.

22. Bowler SD, Mitchell CA, Armstrong JG. Corticosteroids in acute severe asthma: effectiveness of low doses. Thorax 1992; 47: 584-587.

23. Mountain RD, Sahn SA. Clinical features and out- come in patients with acute asthma presenting with hypercapnia. Am Rev Respir Dis 1988; 138: 535539.

24. Wong CS, Pavord ID, Williams J, Britton JR, Tattersfield AE. Bronchodilatator, cardiovascular, and hypokalapemic effects of fenoterol, salbutamol, and terbutaline in asthma. Lancet 1990; 336: 1396-1399.

25. Hansen-Faschen J, Cowen J, Raps EC. Neuromuscular blockade in the intensive care unit. Am Rev Respir Dis 1993, 147: 234-236.

26. American Thoracic Society. Standards for the diagnosis and treatment of COPD and asthma. Official statement of the American Thoracic Society. Am Rev Respir Dis 1987; 136: 225-244.

27. Wasserfallen JB, Schaller MD, Feihl F, Perret CH. Sudden asphyxic asthma: a distinct entity ? Am Rev Respir Dis 1990; 142: 108-111. 